Marquette University

e-Publications@Marquette

College of Education Faculty Research and

Publications

Education, College of

9-1-2016

Leaving Behind Our Preparadigmatic Past:

Professional Psychology as A Unified Clinical Science

Timothy P. Melchert

Marquette University, timothy.melchert@marquette.edu

Accepted version. American Psychologist, Vol. 71, No. 6 (September 2016): 486-496. DOI. (C) 2016

American Psychological Association. Used with permission. 


\title{
Leaving Behind Our Preparadigmatic Past: Professional Psychology as a Unified Clinical Science
}

\author{
Timothy P. Melchert \\ Department of Counselor Education and Counseling Psychology, \\ Marquette University \\ Milwaukee, WI
}

Acknowledgement: The behavioral and neurosciences have made remarkable progress in the past couple decades. Major advances have been made in understanding a wide range of phenomena, from epigenetics and neural plasticity to the nature of cognition, emotion, consciousness, moral reasoning, social behavior, and culture. Indeed, so much has been learned about human psychology recently that current explanations of many psychological mechanisms and processes are markedly different from those considered current just a generation ago.

At the same time that the scientific understanding of psychology was surging forward, however, professional psychology (PP) went through a particularly challenging period. There has always been competition and divisiveness between the theoretical camps in the field, but the seriousness of the conflicts increased in the 1990s. The movement to establish empirically validated treatments was highly contentious and the divisiveness surrounding recovered memories of child sexual abuse was some of the most serious ever in the history of psychology (Loftus \& Davis, 2006). Many leading psychologists were concerned that the conflicts and divisions had become so serious that 
the field might not be able to continue as a single discipline (e.g., Benjamin, 2001; Staats, 2005; Sternberg, 2005). The role of psychologists, counselors, social workers, and other mental health therapists in providing behavioral health care also declined from the 1990 s to the 2000s while the proportion of clients with mental health problems treated by psychiatrists and general medical practitioners increased (Wang et al., 2006).

Professional psychology has made substantial progress in working through several of these issues over the past decade. Contemporary research tends to use stronger designs, measurements, and statistical analyses than what were used in the past, and there is less controversy regarding published research findings as a result. Widespread consensus has also developed regarding the need to apply evidence-based practice guidelines when providing behavioral health care (American Psychological Association [APA] Presidential Task Force on Evidence-Based Practice, 2006). These and other developments have helped rein in issues that might have led to significant controversy in the past, and several observers have noted that conflict and divisiveness in the field have declined generally (e.g., Goodheart \& Carter, 2008).

Beyond these trends, there is also a more fundamental change taking place. Recent research on human behavior has advanced so significantly that the current scientific understanding of human psychology is now fundamentally different from many of the standard approaches PP traditionally used to understand human development, functioning, and behavior change. For example, PP education has often relied on an array of competing theoretical orientations for case conceptualization and other important aspects of clinical training, whereas these orientations are rarely mentioned in current scientific explanations of human development and behavior (these issues are all discussed more extensively in the next two sections). As a result, PP needs to reconsider the standard frameworks and curriculum it uses for education and training in the field. PP needs to keep current with the underlying science, and outdated frameworks and practices need to be identified and replaced based on the best scientific evidence available. 
The main question addressed in this article concerns whether PP needs to undergo a fundamental transition from the era when the traditional theoretical orientations provided the main conceptual foundations for clinical education and practice to an era based instead on an integrated scientific understanding of human psychology. Such a transition would be of historic importance for the field and would result in major changes to PP education and practice. Evaluating whether such a transition needs to take place, however, requires an appreciation of the nature of theory and research in the field. Therefore, this article begins with a brief historical review of theory and research in psychology, so that the earlier approaches can be contrasted with the current scientific understanding of human psychology.

\section{Professional Psychology in the Preparadigmatic Era}

A wide variety of theoretical approaches have been used to understand human development, functioning, and behavior change across the history of PP. Understanding the reasons for this diversity of approaches is important for appreciating the evolution and current status of the field.

\section{The Proliferation of Theoretical Orientations}

When psychology was becoming established as a scientific discipline in the second half of the 19th century, there were two main approaches to understanding mental phenomena. The first of these was mental philosophy. The work of John Locke (1690), who proposed the conceptualization of the mind as a tabula rasa, or blank slate, in 1690, was particularly influential. The second main approach involved the experimental methods that emerged from the scientific revolution, including the anatomical and physiological investigations that were being conducted in biology and medicine (e.g., Hermann Helmholtz's 1850 discovery of the speed of nerve conduction and Paul Broca's 1861 discovery of a brain lesion in a man who had lost the ability to speak; Benjamin, 2014). Fechner's 1860Elements of Psychophysics proved to be a watershed in convincing scientists that it was possible to reliably measure psychological, and not just physiological, 
phenomena and that a science of psychology was consequently possible.

Over the next century, a wide variety of alternative approaches to understanding human psychology were proposed. Freud proposed that it was actually subconscious processes, rather than the conscious mental processes most psychology researchers focused on, that were the important forces driving human psychology. John Watson then argued that neither conscious nor subconscious phenomena were the proper focus of psychology and should be replaced with a focus on behavior. Starting in the 1950s, humanistic theories and, later, cognitive and family systems approaches quickly grew in popularity. In the 1970s, feminist and multicultural approaches became influential, followed by solution-focused therapy, eye movement and desensitization reprocessing, mindfulness-based approaches, motivational interviewing, and others. Combining orientations in an integrative or eclectic fashion also became common in the 1990s and new theoretical systems continue to be proposed (e.g., Henrique, 2011; Magnavita \& Anchin, 2014).

The problem of irreconcilable theoretical orientations for understanding psychological phenomena was recognized right from the start. The most influential critique came in 1913 from John Watson, who pointed out that the existing theoretical orientations fundamentally conflicted in ways that were not resolvable (Watson, $\underline{1913})$. Thomas Kuhn's (1962) model of the evolution of scientific disciplines is often used to explain this complicated situation. Kuhn concluded that psychology was in a preparadigmatic stage of development characterized by many conflicting views and competing explanations for phenomena and disagreements about what is even the proper focus of research. Kuhn argued that a field becomes paradigmatic after the emergence of a major scientific achievement or school of thought (i.e., a paradigm) that convincingly explains phenomena and unites the scientific community in an area.

There are still many signs of preparadigmatic conflicts and practices in contemporary PP. Divides between theoretical camps remain serious (e.g., Shedler, 2010; Sternberg, 2005; Wampold et al., 2010), and none of the theoretical orientations have come to dominate PP or the larger behavioral health care field. Surveys of behavioral 
health professionals consistently find that only a minority, typically less than one third of the sample, endorses a particular theoretical orientation, even an eclectic or integrative approach (Prochaska \& Norcross, 2014). There have also been concerns that the use of some theoretical orientations is potentially harmful. The use of unreliable techniques or unsupported interpretations involving recovered memories of child abuse resulted in numerous allegations of harm in the 1990s (Loftus \& Davis, 2006), and concerns have been raised about several other orientations to clinical practice as well (Lilienfeld, 2007; Norcross, Koocher, \& Garofalo, 2006).

Given the diversity of competing theoretical orientations in PP, the standard approach for therapists to show that their clinical services are competently delivered has been to select a theoretical orientation and learn to apply it consistently in practice. This approach is still evident in current educational practices in the field. For example, the American Psychological Association (APA) Assessment of Competency Benchmarks Work Group (Fouad et al., 2009) identified one of the "essential components" of competent practice as follows: "Formulates and conceptualizes cases and plan interventions utilizing at least one consistent theoretical orientation" (p. S19). To apply to internships listed by the Association of Psychology Postdoctoral and Internship Centers (APPIC), students need to answer the following question on the APPIC Application for Psychology Internship: "Please describe your theoretical orientation and how this influences your approach to case conceptualization and intervention" (APPIC, 2015).

\section{Reasons for the Preparadigmatic Proliferation of Theoretical Orientations}

Though it may seem unusual that a diverse array of competing theoretical orientations for understanding phenomena would develop within a scientific discipline, there are very understandable reasons why this happened in PP. Many of these reasons are generally well known. In addition to the different personalities of the theorists and the different historical and cultural contexts in which they worked are issues more directly related to the nature of scientific theory and research. Four issues are particularly important in this regard (Melchert, 2015). 
First, many of the traditional theoretical orientations in the field are based on philosophical assumptions or first principles (e.g., biologically based drives in Freudian theory, the blank slate of nearly complete malleability in behaviorism, an optimistic self-actualizing tendency in Rogerian theory, a postmodern constructivism in solutionfocused therapy). As a result, accepting the validity of these theories is based largely on accepting their underlying assumptions. Indeed, advice on selecting a theoretical orientation to guide one's approach to clinical practice frequently involves evaluating the fit between the personal worldview of the therapist and the assumptions underlying a theoretical orientation (e.g., Truscott, 2010).

A second reason for the preparadigmatic nature of psychology involves the problem of nonfalsifiability, which was identified by the philosopher of science Karl Popper. As a student in Vienna in 1919, Popper heard both Freud and Einstein present their theories. Though he was highly impressed with both of them, he observed that Freud's was presented in a way that made it amenable to confirmation, whereas Einstein's had testable implications that, if shown to be false, would prove the entire theory wrong. Popper (1963) argued that scientific theories must be falsifiable, and genuine tests of theories involve attempts to refute them.

Another reason why the field remained preparadigmatic as long as it did was the limited power and precision of the scientific tools that were available to investigate the tremendous complexity of human psychology. The power of scientific tools (e.g., telescopes and microscopes) is well known to constrain the scope of the findings that are possible in the natural sciences. The development of practical functional magnetic resonance imaging (MRI) and genomic sequencing machines in the 1990s made it clear that progress in the neuro- and behavioral sciences was also highly dependent on the power and precision of scientific tools.

Another reason why the behavioral sciences remained preparadigmatic as long as they did was the sheer complexity involved. Scientists now routinely refer to the human mind and brain as the most complex system known to exist in the universe. In just a three-pound organ are 86 billion highly connected neurons, each with an average of a thousand or more dendritic connections (Azevedo et 
al., 2009). Together they create feedback mechanisms across the biological, psychological, and sociocultural levels that result in structures and functions that also continually change and evolve. The complexity involved in this system is truly extraordinary compared with any other phenomenon known to exist, and uncovering and explaining this tremendous complexity will naturally take longer than it does to describe and explain most other natural phenomena. This is ultimately the most important reason why psychology remained preparadigmatic longer than the physical and biological sciences.

\section{Emergence of the Behavioral Sciences as Paradigmatic Disciplines}

Despite the truly extraordinary complexity of human behavior, research has advanced dramatically in recent years, and a new scientific understanding of human psychology has emerged that is fundamentally different from what existed previously. There are many scientific advances that exemplify this new perspective, but two developments have been critical in establishing the behavioral sciences as paradigmatic disciplines that are now consistent with the rest of the natural sciences. Without these developments, the behavioral sciences likely would have not yet unified around a paradigmatic understanding of human psychology. One of these developments is theoretical, whereas the other is technical. The theoretical development links psychology with the single greatest theoretical advance ever in biology, namely, evolutionary theory.

\section{Importance of Evolutionary Theory}

The importance of evolution in human development was recognized during the first century after Darwin (1859) published On the Origin of Species in 1859, but it was generally not thought to play a major role in higher level psychological characteristics because humans are so different from other species and culture plays such an important role in our mental life and behavior (Mameli, 2007). Evolution was viewed as responsible for basic innate mental abilities (e.g., sensation, perception, classical and operant conditioning, basic logical and probabilistic reasoning), but our more sophisticated mental 
characteristics were viewed as categorically different from these lower level capabilities. In recent decades, however, that view has changed.

Two major research achievements illustrate how evolutionary theory has become essential for understanding the origins, structure, and function of human psychology across all biopsychosocial levels of natural organization. At the biological level, the very complicated and peculiar structure of the human brain was poorly understood until Paul MacLean (1967) applied an evolutionary perspective and identified three basic structures: the "reptilian brain," comprising the brain stem, cerebellum, and basal ganglia that are very similar to reptile brains; the "mammalian brain" that includes the limbic system, which is prominent in mammals that live in social groups; and the most recently evolved region of the mammalian brain, the cerebral cortex, which is especially highly developed in humans. Subsequent research found that MacLean's original "triune brain" proposal was a simplification that needed substantial refinement (Streidter, 2005), but the highly complicated structure and function of the human brain remained largely a mystery before the application of the evolutionary perspective.

At the sociocultural level, prosocial behavior and altruism were also largely a mystery until relatively recently. It seemed that selfish and antisocial behavior would maximize the survival of individual members of a species, and yet humans and other social animals routinely also demonstrate highly prosocial behavior and even altruism. In 1975, E. O. Wilson noted that this was the greatest theoretical problem in all of sociobiology at that time (Wilson, 1975). The solution to this problem involved changing the focus of evolutionary theory from the reproducing individual to the replicating gene-organisms engage in behavior that promotes survival and replication of the gene, not necessarily the individual organism that carries the gene (Dawkins, 1976). This insight was critical for understanding the competing nature of individual and group selection that favors both selfishness (individual selection) and cooperation (group selection). These competing evolutionary pressures are also the source of many conflicted human emotions and cognitions (anger, competition, tribalism, curiosity, humility, empathy, love) that are at the very core of human psychology (Buss, 2015; Dunbar \& Barrett, 2007; Wilson, 2014). Recent investigations into these types of

American Psychologist, Vol 71, No. 6 (September 2016): pg. 486-496. DOI. This article is @ American Psychological Association and permission has been granted for this version to appear in e-Publications@Marquette. American Psychological Association does not grant permission for this article to be further copied/distributed or hosted elsewhere without the express permission from American Psychological Association. 
questions are resulting in dramatic reconceptualizations of the major role of culture in the evolution of human social behavior (e.g., Morris, 2014; Pinker, 2011).

Many more examples could be presented that show how essential features of human nature are unintelligible without evolutionary theory (for reviews, see Buss, 2015; Dunbar \& Barrett, 2007). At both the level of mechanisms ("proximate explanations of behavior") and the level of "ultimate explanations of behavior," or why life is designed in the manner it is (Tinbergen, 1963), human psychology cannot be understood from a scientific perspective without evolutionary theory. This is true from the level of neuroanatomy and physiology (e.g., MacLean, 1967), to infant attachment (e.g., Bowlby, 1969), to cognition and consciousness (e.g., Gazzaniga, 2011), to intimate and family relationships (e.g., Fisher, 2004), to interpersonal relations and social behavior (e.g., Pinker, 2011). The biologist Theodosius Dobzhansky (1973, p. 125) noted that "nothing in biology makes sense except in the light of evolution," and it is now apparent that the same observation applies to human psychology as well. The behavioral sciences are now fundamentally linked at the theoretical level with the rest of the natural sciences in terms of both proximate and ultimate explanations (Buss, 2015). This is a historic development that, for the first time, unifies psychology around a paradigmatic theoretical perspective that is consistent with the rest of the natural sciences. This perspective may not yet be well integrated into PP education and practice, but it is fully accepted across the behavioral sciences generally as well as the biological and neurosciences (see Buss, 2015; Dunbar \& Barrett, 2007).

\section{Importance of More Powerful Scientific Tools}

A second critical development for establishing the neuro- and behavioral sciences as paradigmatic scientific disciplines has been the invention and use of more powerful and precise scientific tools that have allowed experimental tests of hypotheses that had to remain speculations in the past (Wood et al., 2006). These include both conceptual tools (e.g., new statistical procedures) as well as technical tools (e.g., genetic sequencing machines). For example, the genetic sequencing of individuals' genomes from around the world has found

American Psychologist, Vol 71, No. 6 (September 2016): pg. 486-496. DOI. This article is (C American Psychological Association and permission has been granted for this version to appear in e-Publications@Marquette. American Psychological Association does not grant permission for this article to be further copied/distributed or hosted elsewhere without the express permission from American Psychological Association. 
that all human beings now alive descended from the same parents ( $a$ common mother who lived about 200,000 years ago and a common father who lived about 142,000 years ago; Stringer, 2012). This and related research has overturned common misperceptions about the biological meaning of race (Omi, 2001).

Probably the most revolutionary technology that has propelled recent advances in understanding the human mind and brain was the invention of imaging machines, particularly the development of practical functional MRI (fMRI) in the 1990s. Newer imaging machines such as diffusion tensor MRI and magnetoencephalography are further improving both the spatial and temporal resolution of images of brain function. These new technologies are allowing increasingly precise observations of brain functioning at both micro and macro levels, and these are leading to dramatic advances in understanding a variety of psychological processes. For example, the brain has been found to be far more plastic than what was commonly believed just two decades ago (Davidson \& Begley, 2012). Consciousness has also been found to arise from the interplay of a wide variety of neural structures, many that operate subconsciously, and the finding that the brain makes some decisions before the mind becomes consciously aware of them has raised challenging questions regarding the nature of responsibility and free will (e.g., Gazzaniga, 2011). When Freud and others proposed similar ideas in the past, the scientific tools required to rigorously test them were unavailable. That limitation has now been surpassed and knowledge of human psychology is surging ahead as a result.

Though research in many areas is still in its early stages, the tremendous complexity of human psychology is steadily being uncovered. Of course, it will take decades of additional research to explain the precise nature and function of many psychological mechanisms and processes, and disagreements naturally exist regarding findings that have not yet been well replicated and tested, as is the case in any scientific discipline. It is also difficult to gain an integrated understanding of the existing research because the literature is fragmented as a result of the many specializations involved. Nonetheless, there is no major disagreement regarding the main findings that were mentioned earlier in this section with regard to the importance of evolutionary theory and more powerful scientific tools. Despite all that remains to be discovered, the behavioral and

American Psychologist, Vol 71, No. 6 (September 2016): pg. 486-496. DOI. This article is (C American Psychological Association and permission has been granted for this version to appear in e-Publications@Marquette. American Psychological Association does not grant permission for this article to be further copied/distributed or hosted elsewhere without the express permission from American Psychological Association. 
neurosciences have advanced dramatically and a unified paradigmatic understanding of human psychology has emerged that is consistent with theory and research across the natural sciences (APA Presidential Task Force, 2010). Psychology is no longer a preparadigmatic academic discipline, but has become one of the paradigmatic natural sciences.

\section{Emergence of PP as a Unified Clinical Science}

The recent transition of the behavioral sciences to a unified paradigmatic approach to understanding human psychology compels PP to reexamine its curriculum and clinical frameworks and guidelines so that any aspects that have become outmoded can be updated or replaced. Professional psychologists would all agree that PP is a science-based profession that needs to keep current with scientific advances and update educational and clinical practices that are no longer supported by the best available scientific evidence.

Identifying changes that are needed at this point for PP to keep current with scientific advances will require extensive discussion. Central among the topics that need to be addressed is the theoretical basis for clinical practice. The theoretical foundations underlying PP have been unclear throughout the history of the field, and there has been no consensus regarding the appropriate theoretical orientation or framework that should be applied to inform clinical practice. This problem now appears to have been effectively resolved, however, by the underlying science having reached a unified paradigmatic understanding of human psychology. To facilitate discussion on this and related topics, the following issues are suggested as implications of the current scientific understanding of human psychology that PP could consider for possible integration into education and practice in the field.

\section{A Single, Unified Theoretical Orientation}

For the first time in the history of PP, the preparadigmatic array of conflicting theoretical orientations in the field can now be replaced with a unified paradigmatic scientific understanding of human psychology. If PP embraces this position, it will precipitate the 
reexamination of several long-standing practices within the profession. For example, ever since clinical and counseling psychology became established as professions shortly after World War II, training programs have been given great latitude to decide their curriculum, because there was no consensus regarding a core curriculum or theoretical orientation that students entering the profession should master. This was specifically acknowledged at the 1949 Boulder Conference, where the conferees agreed that there should be a common core but also that there was not "one best way" (Raimy, 1950 , p. 55), and they recommended that the issue be left to universities to decide. This perspective is still reflected in the current APA Commission on Accreditation (2013) Guidelines and Principles of Accreditation, which state that

the accreditation guidelines and principles are specifically intended to allow a program broad latitude in defining its philosophy or model of training and to determine its training principles, goals, objectives, designed outcomes, (i.e., its "mission"), and methods to be consistent with these. Stated differently, the Commission on Accreditation recognizes that there is no one "correct" philosophy, model, or method of doctoral training for PP practice; rather there are multiple valid ones. (p. 4)

The current scientific understanding of human psychology suggests a very different approach. From a paradigmatic scientific perspective, one does not select from an array of competing theoretical orientations or philosophies for understanding natural phenomena. Once falsifiable theories are sufficiently tested and verified using experimental research methods, then preparadigmatic orientations for understanding those phenomena are replaced (e.g., once the germ theory of disease was demonstrated by Pasteur in the second half of the 19th century, miasma ["bad air"] theory and the Hippocratic humoral theory of disease were discarded). Replacing the preparadigmatic theoretical orientations in PP with an integrated, scientific understanding of human behavior is critical for the field to be practiced as a clinical science that is unified around a scientific approach to understanding human psychology and behavioral health care. 
The broad outlines of the current scientific understanding of human psychology are now evident. A very large body of replicated and well controlled research has examined a wide range of psychological processes from micro to macro levels, from epigenetics and neural plasticity to infant attachment, to the nature of consciousness and moral reasoning, to the impacts of social context and culture. These findings have also been integrated into falsifiable higher level theoretical frameworks that are capturing the complexity of human development and behavior in an increasingly comprehensive manner (e.g., Davidson \& Begley, 2012; Fisher, 2004; Gazzaniga, 2011; Greene, 2013; Morris, 2014; Pinker, 2011; Ramachandran, 2011; Sroufe, Egeland, Carlson, \& Collins, 2005; Wilson, 2014). Though these frameworks cannot be discussed in detail here, it is critical to note that they all are based on the observation that human cognition, emotion, and behavior are dependent on underlying biological structures and processes that interact with psychological and behavioral factors, and that these in turn interact with social and cultural factors. Knowledge of the inextricably intertwined biopsychosocial domains of functioning is simply necessary to the scientific understanding of human development and functioning (e.g., Engel, 1977; Melchert, 2015; Wilson, 2014). This is true from the level of neurons (e.g., neural plasticity; Davidson \& Begley, 2012) to the level of the individual organism (e.g., the nature of consciousness; Gazzaniga, 2011) to the level of relationships (e.g., romantic love and parenting; Fisher, 2004) to the level of culture and society (e.g., the dramatically different ways that humans treat each other in modern society compared with previous eras; Pinker, 2011). It is also noteworthy how small a role the traditional theoretical orientations play in current scientific explanations of these various processes.

The current scientific understanding of human psychology is tremendously complex, but there is now overwhelming evidence supporting this perspective. As a science-based profession, PP needs to incorporate this literature into PP education and practice. There is not one correct starting point or sequence for learning this literature. One could start with the sociocultural level of natural organization, particularly because this level has had such a large impact on the recent evolution of biopsychosocial functioning and behavior. The psychological level is often covered relatively thoroughly in PP programs because of the field's traditional emphasis on cognition, Association and permission has been granted for this version to appear in e-Publications@Marquette. American Psychological Association does not grant permission for this article to be further copied/distributed or hosted elsewhere without the express permission from American Psychological Association. 
emotion, and behavior at the level of the individual. The biological level is often covered less well, particularly in terms of proximate and ultimate explanations of behavior. Figuring out how best to systematically cover these three interacting levels in PP education will require significant exploration, but moving forward with implementing this approach could be relatively straightforward. For example, a future version of the APA Commission on Accreditation Guidelines and Principles of Accreditation might allow broad latitude in the educational methods used by training programs (e.g., online and traditional courses), but require that the training principles, goals, and designed outcomes be oriented around the scientific understanding of human psychology - that is, there will be "one 'correct' philosophy of doctoral training for PP practice" (borrowing language from the current guidelines; APA Commission on Accreditation, 2013, p. 4). A future version of the APA Competency Benchmarks might likewise include a standard that would read: "Assesses and evaluates cases and plans interventions based on the scientific understanding of human development, functioning, and behavior change."

\section{Reconciling the Unified Scientific Basis of Psychology with the Many Psychotherapies Available}

For many professional psychologists, the most difficult aspect of the transition to a unified scientific approach to understanding behavioral health care may involve the loss of the traditional theoretical orientations as the basis for conceptualizing clinical cases. In the preparadigmatic era of PP, one's personally adopted theoretical orientation played a major role in informing one's understanding of the whole treatment process from the initial conceptualization of the nature and etiology of clients' problems at assessment, to the treatment plan one recommended, the treatment one provided, and how one evaluated outcomes and effectiveness at the end of treatment. This is still usually considered the standard approach for learning the profession (e.g., as reflected in the APA Competency Benchmarks [Fouad et al., 2009] and the APPIC Application for Psychology Internship [APPIC, 2015]).

Replacing the traditional theoretical orientations with a unified scientific understanding of human psychology would not mean, 
however, that the traditional orientations play no role in behavioral health care. Though these orientations may not provide valid explanations of the mechanisms responsible for behavior change (e.g., even cognitive therapy, one of the most popular of the theoretical orientations, is inadequate for that purpose; Kazdin, 2007), and they clearly do not provide comprehensive explanations of human psychology, they are still very useful. And they will continue to play an essential role in behavioral health care because they describe psychotherapies that have been empirically demonstrated to be safe and effective for achieving behavior change (e.g., APA, 2012). They would not be referred to as theoretical orientations because they do not refer to theories in the falsifiable, scientific sense of the term. They are appropriately referred to as psychotherapies, however, that is, as systems of methods and processes that result in therapeutic improvements in large numbers of cases when applied appropriately. In other words, these therapies might still be found to be effective for ameliorating distress and improving functioning even if their original theoretical formulations are no longer supported as proximate or ultimate scientific explanations of human psychology. Most psychotherapies were developed before recent scientific research uncovered the mechanisms, functions, and origins of many psychological processes, and so it would not be surprising if their preparadigmatic theoretical underpinnings are not always supported by current scientific knowledge.

The scientific foundations of behavioral health care consequently rely on the now-well-established scientific literature that explains human development and functioning as well as the extensive research that has demonstrated the safety and effectiveness of a variety of therapeutic interventions. Knowledge of both these topics is clearly far from complete, however, and particularly regarding the specific mechanisms and processes that result in psychiatric syndromes or that explain therapeutic improvements. To deal with this situation, PP has embraced the principles of evidence-based practice whereby practitioners consider the best available research evidence relevant to a case and integrate that with their clinical experience as well as clients' preferences, values, and culture (APA Presidential Task Force on Evidence-Based Practice, 2006). 
It is important to note that medicine relies on the same evidence-based practice principles as PP because it operates in the same context of incomplete knowledge regarding health, dysfunction, and disease. Medical science has also made dramatic progress, but there is still limited knowledge regarding the cause and cure of many medical conditions (e.g., idiopathic diseases such as Alzheimer's, Parkinson's, Type I diabetes, multiple sclerosis, many cancers, many seizures, and pain syndromes). As a result, ameliorating symptoms caused by these conditions often becomes the treatment goal. Even for diseases that are better understood, existing knowledge may be insufficient to indicate specific treatments. Take, for example, heart disease. Several medications are available to treat heart disease (e.g., anticoagulants, beta blockers, diuretics, statins) as well as a variety of surgeries (e.g., angioplasty, bypasses, stents) and implantable devices (e.g., pacemakers, defibrillators). Behavioral changes are often prescribed as well (e.g., healthy diet, exercise, stress management, smoking and alcohol use reduction). Predicting patients' response to treatment can be very imprecise and consequently a stepped approach is often used where less intensive, invasive, and risky treatments are tried first (Bonow, Mann, Zipes, \& Libby, 2012). Physicians should not base their evaluation and treatment recommendations on the dictates of a personally selected theoretical orientation but instead on the best available scientific knowledge, their prior experience, and patient values (Institute of Medicine, 2001). Despite incomplete knowledge regarding the etiology and treatment of many diseases, medicine nonetheless relies on a single, unified scientific approach to understand health and disease while employing a range of interventions that have been tested for safety and effectiveness. As clinical sciences based ultimately on the same incomplete body of scientific knowledge regarding human biopsychosocial functioning, medicine and PP both now use the same evidence-based approach to maximize the benefits and minimize the risks of health care intervention.

\section{New Training Approaches and Resources}

Transitioning to a paradigmatic scientific approach also raises questions about changes that may be needed in PP education to ensure it is consistent with current scientific knowledge and evidence-

American Psychologist, Vol 71, No. 6 (September 2016): pg. 486-496. DOI. This article is (C American Psychological Association and permission has been granted for this version to appear in e-Publications@Marquette. American Psychological Association does not grant permission for this article to be further copied/distributed or hosted elsewhere without the express permission from American Psychological Association. 
based practice principles. Many psychologists have considered aspects of these questions in detail, but broader discussions (e.g., within our professional organizations) may be needed to evaluate whether systematic changes are necessary to ensure that the field as a whole remains current in terms of education, practice, and research. A possible starting point for these discussions would be to revisit the question of the need for a core curriculum in the field and what it would look like if PP is approached as a unified clinical science (Benjamin, 2001). A useful way to begin this discussion would be to review the historical development of psychology from a preparadigmatic to a paradigmatic science that now has theoretical and empirical foundations that are consistent with the rest of the natural sciences. This could be followed by an examination of the implications of that transition for practicing PP as a unified clinical science (e.g., along the lines suggested by the present discussion).

Discussions will also be needed regarding the appropriate breadth and depth of curricular coverage regarding the interacting biological, psychological, and sociocultural influences on development and behavior. A variety of clinical topics would also need to be examined. For example, as a clinical science, it may be important to give more systematic attention to the epidemiology of behavioral health disorders, the interactions between behavioral and physical health and sociocultural factors, the most effective interventions for addressing different types of behavioral health problems, the prevention of behavioral health and other biopsychosocial problems, and the promotion of biopsychosocial health and functioning (Melchert, 2015). Discussions will likely also focus on the range of skills one should possess to conduct assessment, psychotherapy, and other behavioral health interventions in different types of general and specialized practice settings. The range of skills in research design, measurement, and data analysis that are needed to evaluate research and carry out one's clinical responsibilities also needs to be discussed. New training resources (e.g., textbooks, competency assessments) will need to be prepared, new training models might be considered, and accreditation criteria and licensure standards may need to be updated, as will continuing education programming. These new educational resources and curricula will be especially important for training in integrated primary care (see the section titled Integrated Primary Care). A variety of stakeholder groups would likely be interested in

American Psychologist, Vol 71, No. 6 (September 2016): pg. 486-496. DOI. This article is (C) American Psychological Association and permission has been granted for this version to appear in e-Publications@Marquette. American Psychological Association does not grant permission for this article to be further copied/distributed or hosted elsewhere without the express permission from American Psychological Association. 
examining aspects of these questions that most directly pertain to them (e.g., graduate and internship training programs, health service provider groups, professional societies, accreditation and certification bodies), but it would also be important that these groups communicate with each other to ensure that important considerations are not missed.

The previous section noted the importance of evidence-based practice principles in health care generally. The importance of these principles in PP education specifically is exemplified by one of the most important documents in the field, the Diagnostic and Statistical Manual of Mental Disorders (DSM), a system that is based on limited scientific knowledge but still has significant clinical utility. The third edition of the DSM (American Psychiatric Association, 1980) was developed out of dissatisfaction with the low diagnostic reliability of the earlier editions. It relied on a descriptive, atheoretical approach that emphasized clinician interrater reliability while setting aside questions of etiology, and disorders were included based on voting by committees. Many changes were incorporated into the latest (fifth) edition of the DSM (DSM-5; American Psychiatric Association, 2013), but it, too, relies on the same general approach as earlier editions. Well-known problems with this approach are excessive comorbidity, the proliferation of hundreds of putatively different pathological entities, and the lack of knowledge regarding the biology underlying the pathological syndromes (Cuthbert \& Kozak, 2013). The science of psychopathology, however, has not yet advanced far enough to indicate an alternative approach. The National Institute of Mental Health was well aware of these problems when it launched the Research Domain Criteria project in 2008 to research relationships between dysfunctional behavior and neurobiological systems. Because that and other research has not yet advanced sufficiently, the DSM-5 is widely regarded as the best available classification of mental disorders, despite its limited scientific foundations (Insel \& Lieberman, 2013). Appreciating these issues is critical when PP is approached as a clinical science that relies on the principles of evidence-based practice. 


\section{More Clinical Perspective on Treatment Effectiveness}

The voluminous literature that has accumulated in recent decades regarding the effectiveness of behavioral health care intervention has greatly strengthened the scientific foundations of PP. The general effectiveness of psychotherapy was unclear until Smith and Glass (1977) conducted meta-analyses that compellingly demonstrated that psychotherapy was effective, even "remarkably efficacious" (Wampold, 2001, p. 71). Research further suggests that the effectiveness of psychotherapy often exceeds or is comparable with that of alternative psychopharmacological interventions (APA, 2012). There are still vigorous debates regarding the biopsychosocial mechanisms and processes responsible for behavior change (e.g., the role of common factors vs. specific treatment effects; Wampold et al., 2010). This is not unexpected, however, given that psychological outcomes are multifactorially determined and the process by which individuals change is likely to be complicated as well. But there is no longer significant debate regarding the general effectiveness of psychotherapy.

One consequence of having established the general effectiveness of psychotherapy is likely to be greater attention on objectively evaluating the effectiveness of treatment in the individual case. Currently there is substantial emphasis on using empirically supported treatments as part of evidence-based practice, but additionally monitoring and demonstrating the effectiveness of treatment using standardized outcome measures is likely to grow in emphasis as well. This practice is also important for identifying cases that include deterioration so that treatment can be adjusted to attempt a more beneficial outcome (Barlow, 2010; Lambert, 2010). Examples from medicine are again useful to illustrate the importance of this approach. For many medical conditions, standard practice includes the use of objective outcome measures, and it would be considered entirely inadequate to employ an empirically supported treatment without also systematically monitoring the effects of that treatment on an ongoing basis (e.g., routine blood pressure or blood sugar measurements to monitor the effectiveness of hypertension or diabetes treatment). Of course, many problems and illnesses are not reversed or cured (as is the case in behavioral health care as well). 
Nonetheless, treatments are typically monitored on an ongoing individual basis, modified as needed to maximize effectiveness and minimize risks, and continuing care for chronic conditions can extend for many years. As PP orients more clearly as a clinical science, further movement in this direction is likely as well.

\section{Integrated Primary Care}

Integrated primary care is currently being advocated in the United States and worldwide to improve the effectiveness and efficiency of health care delivery systems, for those with serious physical and mental illness as well as the population in general (e.g., Belar, 2012; Miller \& Prewitt, 2012; World Health Organization, 2008). Patient-centered medical homes and other integrated primary care models are designed to take more holistic, biopsychosocial approaches to the assessment and treatment of physical and mental illness and disease (Nielsen, Langner, Zema, Hacker, \& Grundy, 2012).

There is also growing recognition within medicine of the importance of behavior in the etiology, consequences, and treatment of physical health problems. Indeed, it is estimated that fully $50 \%$ of morbidity and mortality in the United States is caused by behavior and lifestyle factors (Institute of Medicine, 2004). As a result, assessment and treatment in integrated primary care is biopsychosocial in orientation because of the clear interactions between medical, psychological, and sociocultural influences on health and functioning. Utilizing one or some combination of the traditional theoretical orientations to psychological practice can be very difficult or even impossible in these settings; instead, a science-based biopsychosocial approach is necessary (Health Service Psychology Education Collaborative, 2013; Melchert, 2015). If PP does not fill the need for behavioral health expertise in integrated primary care, other professions will.

\section{Conclusions}

Remarkable progress has been made in the scientific understanding of human psychology. Though many psychological phenomena remain only poorly understood at this point, increasingly

American Psychologist, Vol 71, No. 6 (September 2016): pg. 486-496. DOI. This article is (C American Psychological Association and permission has been granted for this version to appear in e-Publications@Marquette. American Psychological Association does not grant permission for this article to be further copied/distributed or hosted elsewhere without the express permission from American Psychological Association. 
detailed explanations of numerous aspects of human development and functioning are steadily accumulating. Psychology is now firmly grounded in experimental findings and tests of falsifiable theories that are thoroughly consistent with the rest of the natural sciences. The speed at which this has occurred has also been remarkable. Indeed, many aspects of the current scientific understanding of human psychology had not yet been discovered just a generation ago. Textbooks from that time typically relied on the traditional theoretical orientations to explain many features of personality, psychopathology, and psychotherapy. Many textbooks in PP still take that approach. Textbooks in the future, however, will undoubtedly have completely different starting points for discussing these topics. They will likely note the historical importance of the traditional theoretical orientations, but will then proceed to discuss the increasingly well established proximate and ultimate scientific explanations of human behavior.

The evolution of psychology to a paradigmatic natural science discipline poses critical questions for PP as well. As a science-based profession, PP needs to identify outmoded frameworks and practices and replace them with approaches consistent with the best available scientific knowledge. Before recent years, there essentially was no alternative but to rely on the various theoretical orientations for guiding clinical practice, because scientific knowledge regarding the tremendous complexity of human psychology was too limited. Now that a paradigmatic scientific understanding has emerged, however, it might be considered irresponsible for PP not to systematically transition to the new scientific framework. Some might be inclined to propose still another theoretical orientation to attempt to capture the expansive and integrative biopsychosocial nature of human behavior, but that would not be a scientific approach. Science is cumulative, building on verified observations and experimental tests of falsifiable theories that explain how natural phenomena are structured and organized and why they function the way they do. New theoretical orientations in PP generally have not been designed to explain phenomena in this manner, but instead typically offer alternative explanations of phenomena based on the proponent's experience and worldview. The regular introduction of new theoretical orientations was a main feature of the preparadigmatic era in psychology, but that era has come to an end.

American Psychologist, Vol 71, No. 6 (September 2016): pg. 486-496. DOI. This article is (C) American Psychological Association and permission has been granted for this version to appear in e-Publications@Marquette. American Psychological Association does not grant permission for this article to be further copied/distributed or hosted elsewhere without the express permission from American Psychological Association. 
NOT THE PUBLISHED VERSION; this is the author's final, peer-reviewed manuscript. The published version may be accessed by following the link in the citation at the bottom of the page.

Though difficult in some ways, transitioning to a unified sciencebased approach to education and practice in the field will be a very welcome development for many psychologists. This has always been, after all, the goal of the profession from the start. It would also mean that many of the perennial preparadigmatic conflicts between the theoretical camps in the field can finally be left behind. More importantly, it would mean that PP would become a true clinical science guided by an integrated body of scientific knowledge that is consistent with the rest of the scientific disciplines and clinical professions. Moving ahead with a unified voice grounded firmly in science will allow PP to more effectively address people's behavioral health and biopsychosocial needs. This is critical not just for the future of the profession but also for the health and well-being of the public who we serve.

\section{Footnotes}

1 George Engel introduced the "biopsychosocial model" in 1977 to counter what he viewed as the overemphasis on biology in medicine. His perspective has been highly influential throughout healthcare and is widely regarded as the appropriate framework through which to understand health and healthcare. It has also been pointed out that he misnamed his approach, however, because he did not propose a model in the scientific sense (i.e., that utilizes observations, rules, and scientific laws to explain a class of phenomena) but instead used the term in its colloquial sense (e.g., McLaren, 1998). Engel's approach technically refers to a metatheoretical framework that points to the range of factors that need to be considered to understand theory and research in medicine (Melchert, 2015). It takes the same general approach as various integrative and eclectic approaches that have been introduced in PP and point to the range of factors that need to be considered to understand human psychology (e.g., Lazarus's, 1976, BASIC-ID framework). But it does not refer to a falsifiable scientific model or theory that explains particular phenomena.

$\underline{2}$ The APA Commission on Accreditation has required that accredited PP training programs address the biological, cognitive and affective, and social bases of behavior since the late 1970s. Programs were given significant latitude in choosing how to cover those topics, however, because though it was obvious that biological, cognitive and affective, and social factors had major influences on behavior, an integrated biopsychosocial understanding that was consistent with the rest of the natural sciences (as described earlier) has only recently emerged. In

American Psychologist, Vol 71, No. 6 (September 2016): pg. 486-496. DOI. This article is (C) American Psychological Association and permission has been granted for this version to appear in e-Publications@Marquette. American Psychological Association does not grant permission for this article to be further copied/distributed or hosted elsewhere without the express permission from American Psychological Association. 
addition, clinical case conceptualization and intervention typically have been based on one's chosen theoretical orientation and not on an integrated understanding of the biopsychosocial basis of behavior. This led to many conflicting perspectives, several of which became highly controversial (e.g., regarding repressed memories of child sexual abuse).

\section{References}

American Psychiatric Association. (1980). Diagnostic and statistical manual of mental disorders (3rd ed.). Washington, DC: Author.

American Psychiatric Association. (2013). Diagnostic and statistical manual of mental disorders (5th ed.). Arlington, VA: American Psychiatric Publishing.

American Psychological Association. (2012). Resolution of psychotherapy effectiveness. Retrieved from www.apa.org/about/policy/resultionpsychotherapy.aspx

American Psychological Association Commission on Accreditation. (2013). Guidelines and principles for the accreditation of programs in professional psychology. Washington, DC: American Psychological Association.

American Psychological Association Presidential Task Force. (2010). Psychology as a core science, technology, engineering, and mathematics (STEM) discipline. Washington, DC: American Psychological Association.

American Psychological Association Presidential Task Force on Evidence-Based Practice. (2006). Evidence-based practice in psychology. American

Psychologist, 61, 271-285. 10.1037/0003-066X.61.4.271

Association of Psychology Postdoctoral and Internship Centers. (2015). Application for psychology internships. Retrieved from http://appic.org/AAPI-APPA

Azevedo, F. A. C., Carvalho, L. R. B., Grinberg, L. T., Farfel, J. M., Ferretti, R. E. L., Leite, R. E. P., . . .Herculano-Houzel, S. (2009). Equal numbers of neuronal and nonneuronal cells make the human brain an isometrically scaled-up primate brain. The Journal of Comparative Neurology, 513, 532-541. 10.1002/cne.21974

Barlow, D. H. (2010). Negative effects from psychological treatments: A perspective. American Psychologist, 65, 13-20. 10.1037/a0015643

Belar, C. D. (2012). Reflections on the future: Psychology as a health profession. Professional Psychology: Research and Practice, 43, 545550. 10.1037/a0029633 
Benjamin, L. T., Jr. (2001). American psychology's struggles with its curriculum. Should a thousand flowers bloom?American

Psychologist, 56, 735-742. 10.1037/0003-066X.56.9.735

Benjamin, L. T., Jr. (2014). A brief history of modern psychology (2nd ed.). Hoboken, NJ: Wiley.

Bonow, R. O., Mann, D. L., Zipes, D. P., \& Libby, P. (2012). Braunwald's heart disease: A textbook of cardiovascular medicine (9th ed.). Philadelphia, PA: Elsevier Saunders.

Bowlby, J. (1969). Attachment and loss: Vol. 1. Attachment. New York, NY: Basic Books.

Buss, D. M. (Ed.), (2015). The handbook of evolutionary psychology (2nd ed.). Hoboken, NJ: Wiley. 10.1002/9781119125563

Cuthbert, B. N., \& Kozak, M. J. (2013). Constructing constructs for psychopathology: The NIMH research domain criteria. Journal of Abnormal Psychology, 122, 928-937. 10.1037/a0034028

Darwin, C. R. (1859). On the origin of species. London, England: John Murray.

Davidson, D. J., \& Begley, S. (2012). The emotional life of your brain. New York, NY: Hudson Street Press.

Dawkins, R. (1976). The selfish gene. New York, NY: Oxford University Press.

Dobzhansky, T. (1973). Nothing in biology makes sense except in the light of evolution. The American Biology Teacher, 35, 125-129. $10.2307 / 4444260$

Dunbar, R. I. M., \& Barrett, L. (Eds.). (2007). Oxford handbook of evolutionary psychology. New York, NY: Oxford University Press.

Engel, G. L. (1977). The need for a new medical model: A challenge for biomedicine. Science, 196, 129-136. 10.1126/science. 847460

Fechner, G. T. (1912). Elements of psychophysics. In B.Rand (Ed.), The classical psychologists (pp. 562-572). Boston, MA: Houghton Mifflin. (Original work published 1860)

Fisher, H. (2004). Why we love: The nature and chemistry of romantic love. New York, NY: Henry Holt.

Fouad, N. A., Grus, C. L., Hatcher, R. L., Kaslow, N. J., Hutchings, P. S., Madson, M. B., . . Crossman, R. E. (2009). Competency benchmarks: A model for understanding and measuring competence in professional psychology cross training levels. Training and Education in Professional Psychology, 3(4, Suppl.), S5-S26. 10.1037/a0015832

Gazzaniga, J. S. (2011). Who's in charge? Free will and the science of the brain. New York, NY: HarperCollins.

Goodheart, C. D., \& Carter, J. A. (2008). The proper focus of evidence-based practice in psychology: Integration of possibility and probability. In W. B.Walsh (Ed.), Biennial review of counseling psychology (Vol. 1, pp. 47-70). New York, NY: Taylor \& Francis.

American Psychologist, Vol 71, No. 6 (September 2016): pg. 486-496. DOI. This article is (C American Psychological Association and permission has been granted for this version to appear in e-Publications@Marquette. American Psychological Association does not grant permission for this article to be further copied/distributed or hosted elsewhere without the express permission from American Psychological Association. 
NOT THE PUBLISHED VERSION; this is the author's final, peer-reviewed manuscript. The published version may be accessed by following the link in the citation at the bottom of the page.

Greene, J. D. (2013). Moral tribes: Emotion, reason, and the gap between us and them. New York, NY: Penguin.

Health Service Psychology Education Collaborative. (2013). Professional psychology in health care services: A blueprint for education and training. American Psychologist, 68, 411-426. 10.1037/a0033265

Henrique, G. (2011). A new unified theory of psychology. New York, NY: Springer. 10.1007/978-1-4614-0058-5

Insel, T. R., \& Lieberman, J. A. (2013, May13). DSM-5 and RDoC: Shared interests. Retrieved from: http://www.nimh.nih.gov/news/sciencenews/2013/dsm-5-and-rdoc-shared-interests.shtml

Institute of Medicine. (2001). Crossing the quality chasm: A new health system for the 21st century. Washington, DC: National Academies Press.

Institute of Medicine. (2004). Improving medical education: Enhancing the behavioral and social science content of medical school curricula. Washington, DC: National Academies Press.

Kazdin, A. E. (2007). Mediators and mechanisms of change in psychotherapy research. Annual Review of Clinical Psychology, 3, 1-27. 10.1146/annurev.clinpsy.3.022806.091432

Kuhn, T. S. (1962). The structure of scientific revolutions. Chicago, IL: University of Chicago Press.

Lambert, M. J. (2010). Prevention of treatment failure: The use of measuring monitoring and feedback in clinical practice. Washington, DC: American Psychological Association. 10.1037/12141-000

Lazarus, A. A. (1976). Multimodal behavior therapy. New York, NY: Springer. Lilienfeld, S. O. (2007). Psychological treatments that cause harm. Perspectives on Psychological Science, 2, 53-70. 10.1111/j.17456916.2007.00029.x

Locke, J. (1690). An essay concerning humane understanding. London, England: Thomas Bassett.

Loftus, E. F., \& Davis, D. (2006). Recovered memories. Annual Review of Clinical Psychology, 2, 469-498. 10.1146/annurev.clinpsy.2.022305.095315

MacLean, P. D. (1967). The brain in relation to empathy and medical education. Journal of Nervous and Mental Disease, 144, 374-382. 10.1097/00005053-196705000-00005

Magnavita, J. J., \& Anchin, J. C. (2014). Unifying psychotherapy: Principles, methods, and evidence from clinical science. New York, NY: Springer.

Mameli, M. (2007). Evolution and psychology in philosophical perspective. In R. I. M.Dunbar \& L.Barrett (Eds.), Oxford handbook of evolutionary psychology (pp. 21-34). New York, NY: Oxford University Press.

American Psychologist, Vol 71, No. 6 (September 2016): pg. 486-496. DOI. This article is (C American Psychological Association and permission has been granted for this version to appear in e-Publications@Marquette. American Psychological Association does not grant permission for this article to be further copied/distributed or hosted elsewhere without the express permission from American Psychological Association. 
NOT THE PUBLISHED VERSION; this is the author's final, peer-reviewed manuscript. The published version may be

accessed by following the link in the citation at the bottom of the page.

McLaren, N. (1998). A critical review of the biopsychosocial model. The Australian and New Zealand Journal of Psychiatry, 32, 86-92. $10.3109 / 00048679809062712$

Melchert, T. P. (2015). Biopsychosocial practice: A science-based framework for behavioral health care. Washington, DC: American Psychological Association. 10.1037/14441-000

Miller, J. E., \& Prewitt, E. (2012). Reclaiming lost decades. Alexandria, VA: National Association of State Mental Health Program Directors.

Morris, I. (2014). War! What is it good for? Conflict and the progress of civilization from primates to robots. New York, NY: Farrar, Straus \& Giroux.

Nielsen, M., Langner, B., Zema, C., Hacker, T., \& Grundy, P. (2012). Benefits of implementing primary care patient-centered medical home: $A$ review of cost and quality results, 2012. Washington, DC: PatientCentered Primary Care Collaborative. Retrieved from http://www.pcpcc.net/sites/default/files/media/

Norcross, J. D., Koocher, G. P., \& Garofalo, A. (2006). Discredited psychological treatments and tests: A Delphi poll. Professional Psychology: Research and Practice, 37, 515-522. 10.1037/07357028.37.5.515

Omi, M. (2001). The changing meaning of race. In N. J.Smelser, W. J.Wilson, \& F.Mitchell (Eds.), American becoming: Racial trends and their consequences (pp. 243-263). Washington, DC: American Academy Press.

Pinker, S. (2011). The better angels of our nature: Why violence has declined. New York, NY: Penguin.

Popper, K. (1963). Conjectures and refutations: The growth of scientific knowledge. London, UK: Routledge.

Prochaska, J. O., \& Norcross, J. C. (2014). Systems of psychotherapy: A Transtheoretical analysis (8th ed.). Belmont, CA: Thompson Brooks/Cole.

Raimy, V. C. (Ed.). (1950). Training in clinical psychology. Englewood Cliffs, NJ: Prentice Hall.

Ramachandran, V. S. (2011). The tell-tale brain: A neuroscientist's quest for what makes us human. New York, NY: Norton.

Shedler, J. (2010). The efficacy of psychodynamic psychotherapy. American Psychologist, 65, 98-109. 10.1037/a0018378

Smith, M. L., \& Glass, G. V. (1977). Meta-analysis of psychotherapy outcome studies. American Psychologist, 32, 752-760. 10.1037/0003066X.32.9.752

Sroufe, L. A., Egeland, B., Carlson, E. A., \& Collins, W. A. (2005). The development of the person: The Minnesota Study of Risk and Adaptation from Birth to Adulthood. New York, NY: Guilford Press.

American Psychologist, Vol 71, No. 6 (September 2016): pg. 486-496. DOI. This article is (C American Psychological Association and permission has been granted for this version to appear in e-Publications@Marquette. American Psychological Association does not grant permission for this article to be further copied/distributed or hosted elsewhere without the express permission from American Psychological Association. 
NOT THE PUBLISHED VERSION; this is the author's final, peer-reviewed manuscript. The published version may be

accessed by following the link in the citation at the bottom of the page.

Staats, A. W. (2005). A road to, and philosophy of, unification. In R.

J.Sternberg (Ed.), Unity in psychology: Possibility or pipedream? (pp. 159-177). Washington, DC: American Psychological Association. 10.1037/10847-010

Sternberg, R. J. (2005). Unifying the field of psychology. In R. J.Sternberg (Ed.), Unity in psychology: Possibility or pipedream? (pp. 3-14). Washington, DC: American Psychological Association. 10.1037/10847001

Streidter, G. F. (2005). Principles of Brain Evolution. Sunderland, MA: Sinauer Associates.

Stringer, C. (2012). Lone survivors: How we came to be the only humans on earth. New York, NY: St. Martin's Press.

Tinbergen, N. (1963). On the aims and methods of ethology. Zeitschrift für Tierpsychologie, 20, 410-433. 10.1111/j.1439-0310.1963.tb01161.x

Truscott, D. (2010). Becoming an effective psychotherapist: Adopting a theory of psychotherapy that's right for you. Washington, DC: American Psychological Association. 10.1037/12064-000

Wampold, B. E. (2001). The great psychotherapy debate: Models, methods, and findings. Mahwah, NJ: Erlbaum.

Wampold, B. E., Imel, Z. E., Laska, K. M., Benish, S., Miller, S. D., Flückiger, C., . . .Budge, S. (2010). Determining what works in the treatment of PTSD. Clinical Psychology Review, 30, 923-933. 10.1016/j.cpr.2010.06.005

Wang, P. S., Demler, O., Olfson, M., Pincus, H. A., Wells, K. B., \& Kessler, R. C. (2006). Changing profiles of service sectors used for mental health care in the United States. The American Journal of Psychiatry, 163, 1187-1198. 10.1176/ajp.2006.163.7.1187

Watson, J. B. (1913). Psychology as the behaviorist views it. Psychological Review, 20, 158-177. 10.1037/h0074428

Wilson, E. O. (1975). Sociobiology. Cambridge, MA: Belknap Press.

Wilson, E. O. (2014). The meaning of human existence. New York, NY: Norton.

Wood, C. C., Berger, T. W., Bialek, W., Boahen, K., Brown, E. N., Holmes, T. C., . . Sweedler, J. V. (2006). Steering Group Report: Brain science as a mutual opportunity for the physical and mathematical sciences, computer science, and engineering. Arlington, VA: National Science Foundation.

World Health Organization. (2008). Primary health care: Now more than ever. Geneva, Switzerland: Author.

American Psychologist, Vol 71, No. 6 (September 2016): pg. 486-496. DOI. This article is (C) American Psychological Association and permission has been granted for this version to appear in e-Publications@Marquette. American Psychological Association does not grant permission for this article to be further copied/distributed or hosted elsewhere without the express permission from American Psychological Association. 